ANO 10 • NÚMERO 19 • 2os sem 2013 • ORGANICOM

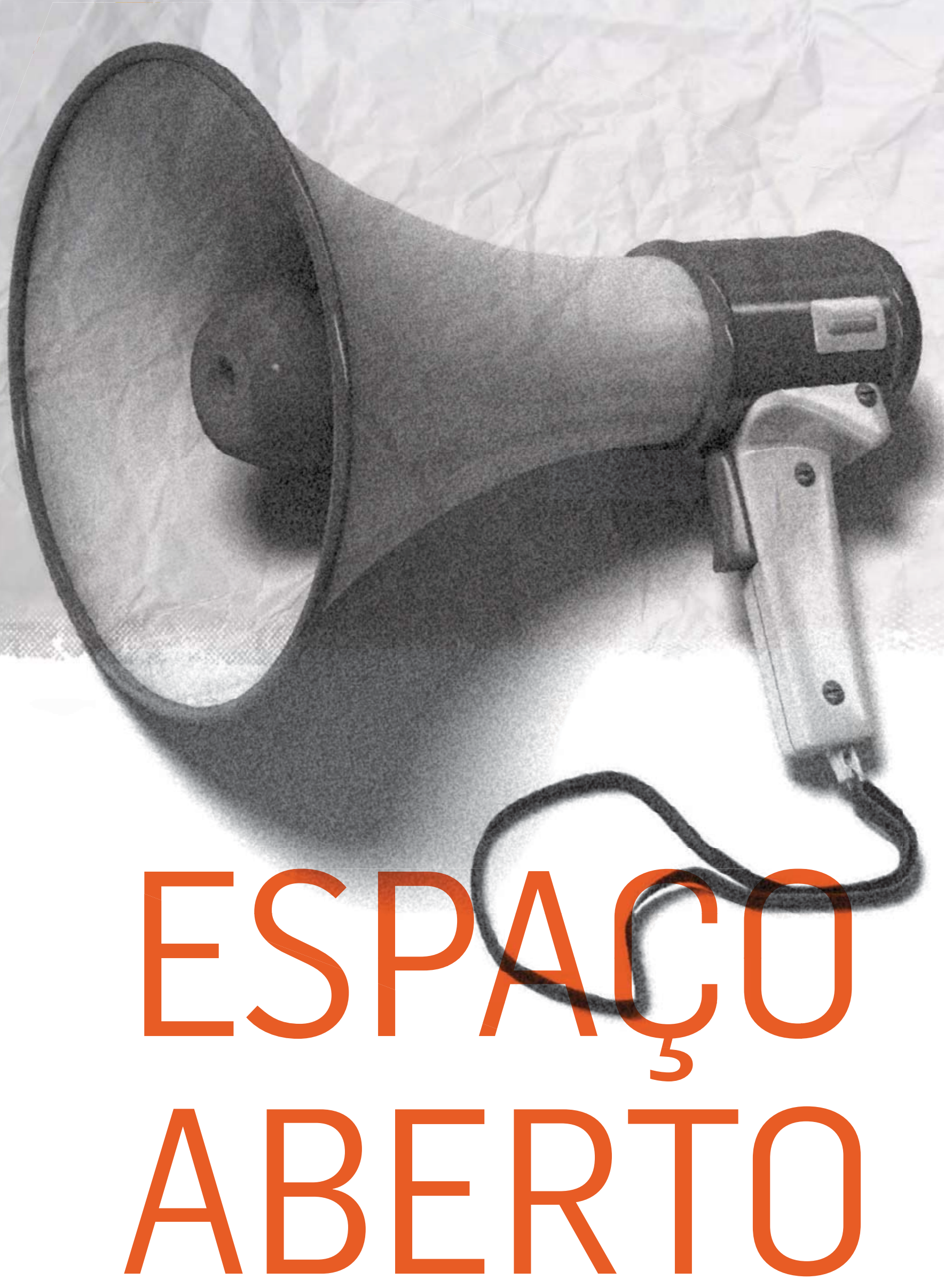




\section{Comunicação pública e comunicação política: por uma interação entre cidadania e democracia}

Public communication and political communication:

for an interaction between citizenship and democracy

Comunicación pública y comunicación política:

por una interacción entre ciudadanía y democracia

Heloiza Helena Matos e Nobre

- Pós-doutora pela Université Stendhal, França, em 1995 e 2007

- Doutora e mestre em Ciências da Comunicação pela Escola de Comunicações e Artes da Universidade de São Paulo (ECA-USP)

- Jornalista pela Universidade Federal de Juiz de Fora (UFJF)

- Professora da ECA-USP

- E-mail: heloizamatos@gmail.com

\section{(9) Guilherme Fráguas Nobre}

- Pós-doutor pela Université Stendhal, França, em 2006

- Doutor em Ciências da Comunicação pela Escola de Comunicações e Artes da Universidade de São Paulo (ECA-USP)

- Mestre em Economia pela Universidade Federal do Paraná (UFPR)

- Economista pela Universidade Federal de Minas Gerais (UFMG)

- Visiting scholar na McMaster University, Canadá, em 2010

- Pesquisador do Instituto Ciência-Tecnologia da Comunicação

- E-mail: fraguasnobre@gmail.com 


\section{Resumo}

O artigo objetiva relacionar seis variáveis entre si, a saber: capital social, capital comunicacional, comunicação pública, comunicação política, cidadania e democracia. As hipótese básicas são: 1) 0 capital social e 0 capital comunicacional possibilitam a comunicação pública; 2) existe uma passagem da comunicação pública (instância deliberativa) para a comunicação política (instância de ação); 3) a cidadania, ao implicar os referidos capitais e comunicações, conduziria à democracia participativa (em relativo contraste com a democracia representativa).

PALAVRAS-CHAVE: CAPITAL SOCIAL • CAPITAL COMUNICACIONAL • COMUNICAÇÃO PÚBLICA • COMUNICAÇÃO POLITICA • CIDADANIA • DEMOCRACIA.

\section{Abstract}

The purpose of the article is to establish the relationship of these six variables with one another: social capital, communication capital, public communication, political communication, citizenship and democracy. Basic assumptions are as follows: 1) social capital and communication capital enable public communication; 2) there is a transition from public communication (sphere of deliberation) to political communication (sphere of action); 3) citizenship, by involving those capitals and communications, would lead to participatory democracy (in contrast to representative democracy).

KEYWORDS: SOCIAL CAPITAL • COMMUNICATION CAPITAL • PUBLIC COMMUNICATION • POLITICAL COMMUNICATION • CITIZENSHIP • DEMOCRACY.

\section{Resumen}

El artículo trata de la relación entre seis variables: el capital social, el capital comunicacional, la comunicación pública, la comunicación política, la ciudadanía y la democracia. Las hipótesis básicas son: 1) el capital social y el capital comunicacional posibilitan la comunicación pública; 2) hay un pasaje de la comunicación pública (deliberativa) para la comunicación política (acción); 3) la ciudadanía, mediante la participación de los capitales y de las comunicaciones, se traduciría en una democracia participativa (en contraste con la democracia representativa).

PALABRAS CLAVES: CAPITAL SOCIAL • CAPITAL COMUNICACIONAL • COMUNICACIÓN PÚBLICA • COMUNICACIÓN POLÍTICA • CIUDADANÍA • DEMOCRACIA. 
artigo propõe analisar como os cidadãos contemporâneos têm se mobilizado para se governarem e aos gestores públicos, utilizando como principais recursos disponíveis o capital social e o capital comunicacional. A democracia (governo pelos cidadãos) requer o exercício da cidadania, o que levaà questão: de que modo os cidadãos contemporâneos têm exercido sua cidadania? No passado como agora, essa condição implicava cidadãos empenhados em discutir os assuntos públicos, para, juntos, deliberarem sobre normas e ações. A forma e o local dessa interação se modificaram: a ágora ampliou-se em "esfera pública" e o discurso presencial em viva-voz evoluiu, graças aos meios de comunicação e ao uso intensivo das tecnologias, para a comunicação pública e a comunicação política.

Assim, a esfera pública veio incluir instâncias presenciais e virtuais, analógicas e digitais onde espaço, tempo e corporalidade se relativizam para permitir interações múltiplas, de via simples ou multidirecionais, entre agentes privados ou institucionais; e a comunicação pública passou a representar as interações que por aí circulam, tendo sua origem no interesse público, sua meta na melhora da vida em comum, e suas regras processuais ancoradas no direito universal à expressão, no debate equilibrado, na deliberação cooperativa, e na tomada de decisão compartilhada. Essa comunicação pública na esfera pública conduziria, então, à comunicação política, a "palavra que empodera o cidadão" - a comunicação que efetiva a gestão da propriedade pública.

O desafio aqui é entender como os cidadãos têm exercido a comunicação pública (poder de interação) e a comunicação política (poder de intervenção) para governar, via esfera pública, a coisa pública - incluindo representantes eleitos e gestores públicos. Trata-se, pois, de um empreendimento gerencial: cidadãos governando juntos, via comunicação, 0 interesse público. Isso traz para um primeiro plano a "comunicação". Logo, é preciso investigar como essas modalidades de capital (social e comunicacional) conduzem às comunicações pública e política, no quadro mais amplo de uma cidadania que efetiva a democracia; ou seja, de cidadãos que comunicam e agem para governar a coisa pública e a vida em comum.

\section{BASE TEÓRICA E CONCEITOS FUNDAMENTAIS}

Para compreender a passagem da participação cidadã para a governança cidadã, e como a troca simbólica no âmbito da comunicação pode conduzir a ações práticas no âmbito da política, será preciso fundamentar os conceitos e processos do capital social, do capital comunicacional, da comunicação pública e da comunicação política.

\section{Capital social}

A primeira análise sistemática do conceito de capital social é de Pierre Bourdieu (1980, p. 2), que o definiu como "o conjunto de recursos atuais e potenciais que estão ligados à posse de uma rede durável de relações mais ou menos institucionalizadas de conhecimento e reconhecimento mútuo".

Outros autores tomam-no como componente da ação coletiva (Ponthieux, 2006). Alejandro Portes identifica 0 capital humano com o conhecimento e as habilidades adquiridas pelo indivíduo, enquanto o capital social se relacionaria com a dimensão e a qualidade das relações sociais. "Para possuir capital social, um indivíduo precisa se relacionar com outros, e são estes - não o próprio - a verdadeira fonte dos seus benefícios" (Portes, 2000, p. 139). Na prática, o 'volume' de capital social seria identificado com o nível de envolvimento associativo, ou seja, que o indivíduo pertença a uma comunidade civicamente engajada, participando em variadas redes de interação.

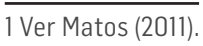


Outra característica é que o capital social pode designar um conjunto de sociabilidades ou configurações relacionais específicas (Granjon; Lelong, 2006). Seria, ao mesmo tempo, um recurso e um instrumento de poder, que se aplica tanto ao indivíduo como a uma coletividade (família, vizinhança, etnias, nação etc.). 0 capital social seria o resultado de uma escolha racional ou o efeito da vida social, podendo ser de ordem pública ou privada.

Para Pippa Norris (1996), o capital social pode ser entendido como as densas redes de normas e de confiança social que capacitam os participantes a cooperar na busca de objetivos compartilhados. Segundo a autora, quanto mais nos conectamos com outras pessoas, em uma interação face a face através da comunidade, mais confiamos nelas.

0 conceito do capital social tem como fundamento a obra Democracia na América, de Tocqueville, para analisar os padrões de engajamento cívico e política; e a obra A ética protestante e o espírito do capitalismo, de Max Weber, para compreender as possíveis relações entre as modalidades associativas na América.

Antoine Bévort e Michel Lallement (2006) citam o artigo "Making democracy", de Robert D. Putnam², como o ponto decisivo para o desenvolvimento de numerosos estudos correlacionando o índice de capital social com os níveis educacionais, nutricionais, de saúde e de emprego.

\section{Capital comunicacional ${ }^{3}$}

O conceito de capital comunicacional tem sido empregado com sentidos diversos e para propósitos pouco homogêneos. A despeito disso, já existem esforços para compilar e comparar essas múltiplas propostas de definição (Matos; Nobre, 2009). Após reunir as principais contribuições na área (ver Tabela 1), Nobre e Matos (2010) avançam para sugerir uma definição unificada para capital comunicacional.

Tabela 1 - Definições de capital comunicacional.

\begin{tabular}{|c|l|}
\hline AUTOR & DEFINIÇÃO \\
\hline Malmelin 1 & Ativos físicos de comunicação \\
\hline Hytönen & Estruturas comunicacionais, competências organizacionais/comunicacionais e cultura organizacional \\
\hline Malmelin 2 & Sistemas comunicacionais, competência comunicacionais e relações \\
\hline Gabriela/Marcel & Marca e identidade-cultura organizacional para criar e consolidar a imagem \\
\hline Malmelin 3 & Informação documentada; os sistemas gerenciais e culturais da organização \\
\hline Smith/Coutant & Capital interacional, habilidades de interação \\
\hline Mulholland & Interações face a face \\
\hline Thurlow & Aptidão e poder necessários para lidar com uma realidade contemporânea complexa \\
\hline House of Representatives/NCA & Clima compassivo, empático, respeitoso e comunicativo \\
\hline Aggestam & Criação e alavancagem de conhecimento e know-how \\
\hline Csepeli/Csere & Pode ser medido por padrões de network social \\
\hline Murphet & Capacidade de determinar e gerenciar as fantasias coletivas \\
\hline Jeffres & Conectando pessoas e facilitando a solução de problemas comunitários \\
\hline Silván & Apoio psicológico/espiritual de pessoas que compartilham alegrias e desafios comuns \\
\hline &
\end{tabular}

2 Ver obras de Putnam nas referências finais

3 Ver: Matos e Nobre, 2009; Nobre, 2011. Para referências bibliográficas dos autores da tabela 1, ver Nobre e Matos, 2010.0 conceito de capital comunicacional não está consolidado, figurando relativamente difuso na literatura. 
Assim, pode-se definir capital comunicacional como: uma conjunção de ativos/estruturas/sistemas que, ao contribuírem para a instituição e a promoção da identidade/imagem/cultura, criam um ambiente de compartilhamento e apoio mútuo, onde informações/relacionamentos/conversas são gerados de maneira a desenvolver competências e conhecimentos de caráter coletivo/comunitário/social, com o objetivo final de criar valor para todos os membros da sociedade. Em suma: 0 capital comunicacional é a base material e simbólica da comunicação, mobilizada, por meio de processos sociais interativos e participatórios, para gerar valor.

\section{Comunicação pública}

A esfera pública se consolida a partir de um ideal em que o debate se realiza entre pessoas com igual oportunidade de acesso, em livre argumentação e dotadas de uma capacidade argumentativa racionalizada a ponto de, juntas, alcançarem um entendimento sobre seus problemas. Um conjunto de procedimentos realizados nessa ambiência configuraria um poder comunicativo e permitiria, então, que as demandas localizadas na periferia da estrutura social pudessem alcançar o centro do sistema - ou seja, o poder administrativo (Habermas, 1997). Assim, "a esfera pública é também um espaço intermediário entre as discussões políticas conduzidas pelos atores administrativos centrais e as conversações entre os atores cívicos periféricos" (Marques, 2009).

O conceito de público está relacionado ao interesse comum (e não privado), ou seja, à intenção de defesa do societal e não do societário (Nobre, 2011). A defesa se dá por meio do debate, e este se realiza em diferentes e múltiplas esferas. Para que se processe, o debate deve ter visibilidade, permitir a inclusão e a participação de diferentes atores em comunicação. Nesse sentido, "trata-se de uma comunicação eminentemente democrática, pela profundidade de sua natureza e por sua vocação" (Jaramillo López, 2011). Estes parecem ser pontos consensuados entre diferentes autores que tratam dos conceitos em comunicação pública no Brasil (Kunsch, 2011; Duarte, 2011; Weber, 2011). A questão mais controversa entre diferentes abordagens se localiza, então, em torno dos cenários em que a comunicação pública se torna possível e se materializa.

Pierre Zémor (2005) enfatiza a centralidade do Estado, como instituição política e administrativa, no encaminhamento da comunicação pública. Sua abordagem é a de normatização das ações do governo, numa exigência de um espírito público como o norteador das ações pragmáticas de difusão de mensagens, de atendimento ao cidadão e de elaboração de políticas públicas. 0 autor conclama as instituições de governo a uma comunicação cívica, no sentido de diferenciar uma comunicação governamental guiada por interesses políticos particulares. Mas, ao apresentar uma exigência normativa às instituições do poder central, há o risco de tratar a comunicação pública circunscrita a determinados limites burocráticos.

López (apud Koçouski, 2012) descreve cinco dimensões da comunicação pública: política, organizacional, mediática, estatal e da vida social. A comunicação governamental estaria vinculada ao cenário ou dimensão estatal, onde devem imperar os princípios normativos em prol de uma ação de governo mais cívica, como propõe Zémor (2005). Mas, em função de traumas da tradição política brasileira, há um conjunto de estudiosos que encampam a defesa de um serviço estatal comprometido com os princípios democráticos (Weber, 2011; Kunsch, 2011). Nesse intuito, acabam por restringir a abordagem de uma comunicação pública a um conjunto de regras e compromissos voltados restritamente ao exercício da comunicação em esferas de governo.

4 Ver Gil, Patrícia; Nobre, Heloiza (2013). 


\section{Comunicação política ${ }^{5}$}

María José Cañel (1999) procurou reunir os pontos em comum entre as conceituações da comunicação política. Constatou que se destaca o caráter comunicativo da expressão, por tratar-se de uma atividade que pressupõe um "intercâmbio de mensagens e de símbolos entre aqueles que dela participam". Essa forma de comunicação adquire caráter político devido às consequências (intencionais ou não) que provocam sobre a cena política.

Um problema seria a restrição das definições à emissão e recepção de mensagens políticas. Paraa maior parte, "a comunicação política surge quando a comunicação exerce seus efeitos sobre a política". Assim, parece ser desprezado o contexto em que as mensagens políticas são produzidas. Gilles Achache (1990) ressalta que qualquer modelo de comunicação política, por simples que seja, é um modelo comunicativo que, como tal, deve combinar ao menos quatro fatores: os emissores, os receptores, um espaço público e os meios de comunicação.

Cañel (1999, p. 23-24) propõe, igualmente, uma definição simples e abrangente:

Comunicação política é o campo de estudos que compreende a atividade de determinadas pessoas e instituições (políticos, comunicadores, jornalistas e cidadãos) nas quais se produz um intercâmbio de informações, ideias e atitudes que envolvem os assuntos públicos. Em outras palavras, a comunicação política é o intercâmbio de signos, sinais ou símbolos de qualquer espécie, entre pessoas físicas ou sociais, com o que se articula a tomada de decisões políticas, assim como a aplicação destas na sociedade.

No Brasil, as pesquisas em comunicação política têm passado por uma evolução significativa, refletindo sobre diversos temas contemporâneos: processos eleitorais, marketing político (Figueiredo, 2008), análises de cenários políticos, importância da mídia de massa, imagem política, questões sobre a esfera pública política, processos democráticos e cidadania, além de articulações entre esses temas com a ciência política, e processos deliberativos. Nos últimos anos, a comunicação política tem também acompanhado as transformações da política pela internet (Recuero, 2009; Maia, Gomes e Marques, 2011), como: 'interação', redes sociais, e outros avanços da web 2.0.

Pesquisas mais recentes em comunicação política têm privilegiado as metodologias de survey, meta-análise, análise de conteúdo, análise de discurso, análise de rede e deliberação, análise comparativa, além de experimentos. Particularmente, sobressaem o uso de técnicas estatísticas (Bucy; Holbert, 2011) e o interesse crescente pela pesquisa empírica (Braga; Lopes; Martino, 2010). As temáticas de cidadania e democracia têm sofrido notável releitura (Correia; Ferreira; Santo, 2010).

\section{EM BUSCA DE INTERAÇÕES ENTRE OS CONCEITOS}

Para entender como as modalidades de capital (social e comunicacional) e de comunicação (pública e política) se articulam com os conceitos de cidadania e democracia, pode-se propor uma análise em quatro momentos particulares:

\section{1) O capital social e o capital comunicacional estão na base da comunicação pública e da comunicação política}

O capital social e o capital comunicacional têm em comum o termo "capital", que remete às características de um ativo econômico: uma reserva de valor, um potencial para troca e uma unidade de medida. 0 capital social seriam os recursos 
sociais potencialmente disponíveis para mobilização e engajamento. 0 capital comunicacional seriam os recursos materiais (mídias, veículos) e simbólicos disponíveis para a criação de valor social, político, econômico etc.

Poder-se-ia dizer que a comunicação pública é cidadã e que a comunicação política é democrática. A comunicação pública é cidadã porque visa a uma interação para um acordo de saber entre cidadãos: um entendimento comum acerca de assuntos relevantes na esfera deliberativa pública. A comunicação política é democrática porque visa a uma interação para uma ação entre gestores da coisa pública: uma decisão e a aplicação dessa decisão na pólis. Assim, a comunicação pública seria comparativamente mais intensiva no uso de capital comunicacional; e a comunicação política seria relativamente mais intensiva no uso de capital social.

Não se trata de exclusividade, mas de ênfase. Uma cooperação para a convergência da compreensão demanda, via debate, superior capacidade retórica - referência ao capital comunicacional na comunicação pública. Já uma cooperação para a convergência da ação requer, via processo decisório, maior maleabilidade para alianças - referência ao capital social na comunicação política. Por outro lado, o papel do capital social na comunicação pública seria o de prover o network sobre 0 qual mobilizar e engajar para o debate na esfera pública; e o papel do capital comunicacional na comunicação política seria o de prover o nível de performance requerido para mobilizar e engajar para a ação na coisa pública.

Capital social é o valor do network em si, um valor que já foi conquistado ao longo do tempo e que adquire o caráter diverso de simpatia, apreço, reconhecimento, respeito etc. É um capital em estoque. Por sua vez, o capital comunicacional é 0 vir-a-ser do valor, dependente da competência para usar símbolos e mídias para gerar valor - na forma de entendimento, convencimento, reputação etc. São esses dois capitais que estão na base da transição da comunicação pública (debate para a convergência do entendimento) para a comunicação política (decisão para a convergência da ação).

\section{II) A comunicação pública, enquanto epítome do engajamento cívico, envolve a expressão, o debate, a deliberação e a decisão na esfera pública}

Para fins didáticos, tem-se feito a diferenciação entre cidadania (esfera de debate) e democracia (esfera de ação). Vale insistir: a cidadania implicaria restringir-se a interações simbólicas, enquanto que a democracia implicaria restringir-se a interações materiais. Em resumo: o mundo do símbolo versus o mundo da ação. Numa tentativa de romper tal simplificação artificial, caberia perguntar: existe ação na esfera de debate, e existe debate na esfera da ação?

Sim. Por exemplo, existe ação para: mobilizar e engajar os cidadãos na discussão de temas relevantes, alimentar e conduzir o debate na esfera pública, deliberar após todos terem expressado seus pontos de vista e posições, e no decidir acerca deste ou daquele partido. Na comunicação pública as ações pertencem eminentemente à instância comunicacional - daí a importância do capital comunicacional para a comunicação pública. Por outro lado, o capital social contribui tanto para ampliar a base de cidadãos no debate (inclusão), quanto para articular alianças em torno de partidos que vão se configurando no debate (posição). Mas a ação última (o mútuo entendimento), aqui, será sempre comunicacional - sendo, portanto, simbólica.

Pode-se até propor a terminologia de protodemocracia, isto é, a que governa as ações comunicativas na esfera pública (comunicação pública) - o prefixo proto designando a que vem primeiro. Logo, a comunicação pública pode ser pensada como um embate político de ideias e discursos, em que os cidadãos trabalham juntos para chegar a um entendimento. Neste 
sentido restrito, seria democracia por tratar do governo, não da coisa pública, mas da palavra pública. Cabe à comunicação pública produzir um acordo acerca dessa palavra pública; que será, depois, levada para a esfera política - que a vai traduzir em ação concreta na sociedade. Daí sobressaem as protoações, digamos assim, que garantam o número e perfil dos cidadãos envolvidos, bem como a variedade e o tipo das expressões efetuadas ao longo do debate. Cidadania pressupõe cidadãos competentes e atuantes: social e comunicacionalmente.

\section{III) A comunicação política, enquanto epítome da governança cívica, mobiliza recursos materiais para uma ação efetiva na sociedade}

Vale notar que se tem usado o termo democracia sozinho, sem adjetivos. A intenção é ressaltar-lhe o caráter de governo pelo povo, a gerência pelos cidadãos. Quando se evocam versões adjetivadas, como democracia representativa, incorre-se na discussão sobre o caráter desse governo, sobre a forma que ele pode ou vai assumir. Democracia sem adjetivos acentua 0 perfil de universalização de acesso e participação que desejamos - ao mesmo tempo um direito e um dever de cada cidadão. Essa abordagem permite encarar a comunicação política como uma função social ampliada, ubíqua. Cada cidadão vai à esfera pública decidir o saber, e cada cidadão vai à esfera política decidir o fazer.

Assim, a comunicação pública envolve a política, pois os cidadãos estão tentando governar, juntos, a discussão dos temas públicos; e a comunicação política envolve o debate, pois estão tentando decidir, juntos, a ação sobre a coisa pública. Há, sim, debate na esfera da ação. Os debates na comunicação pública (o que saber) alimentam os debates na comunicação política (o que fazer). A comunicação pública debateria e decidiria sobre assuntos em nível de discurso; enquanto a comunicação política debateria e decidiria sobre como verter tais discursos em prática. Por exemplo, existe debate sobre como agir para: propor políticas de ação, escolher a melhor política, implementar a política escolhida, fiscalizar o fiel cumprimento da política implementada.

Pode-se dizer que o cidadão tem, na comunicação pública, o dever de participar e o direito de decidir; e na comunicação política, o dever de decidir e o direito de governar. Tal raciocínio conduz a uma cidadania obrigatória/absoluta, mas a uma democracia facultativa/relativa - o que se adequaria aos padrões em voga: do ponto de vista do governo, voto obrigatório; do ponto de vista do cidadão, governo representativo. Por difícil que seja tal questão, o desafio ainda é: como trazer, via capital social e comunicacional, a comunicação pública e política para a prática da vida em sociedade?

\section{IV) Cidadania evolui para democracia, e cidadãos (por meio da comunicação pública e da comunicação política) governam a coisa pública}

A interface cidadania e democracia representa a alocação de recursos (sociais e comunicacionais) para obter o necessário efeito sobre acordos (simbólicos) e ações (materiais), tendo por objeto os assuntos públicos e a coisa pública e por agentes, os cidadãos. Tais recursos são movimentados em ambiente específico (esfera pública e política) e sob regras restritas de interação (debate e decisão). Portanto, é bem-vinda a ideia de que a democracia representativa pudesse estar fortalecendo seu lado substantivo (democracia) em detrimento do lado adjetivo (representativa). A Primavera Árabe e os recentes acontecimentos no Brasil poderiam sinalizar tal movimento. 
Assim, o que se observa são pessoas e grupos que vão às ruas para expressar seu descontentamento, desacordo, e para propor mudanças e políticas. A esfera pública se materializa na rua e nos prédios públicos - que são ocupados fisicamente e que passam a ocupar virtualmente as mídias; ao tempo em que a comunicação pública se confunde com a comunicação política, pois há uma cacofonia de debates e decisões. Se uns gritam palavras de ordem, outros silenciam, e há quem traga um discurso coerente; e só se pode dizer que o debate existe porque, em contrapartida, e às vezes de forma assincrônica, há reação social e das autoridades. Há interlocução. Mas tal cacofonia tem provocado decisões práticas. Para além da esfera discursiva (comunicação pública), os movimentos têm conseguido que instâncias do governo se decidam por novos cursos de ação (comunicação política), como: queda do preço de transporte público, importação de médicos, reserva de royalties do petróleo para a saúde e educação etc.

0 papel das mídias sociais em tais protestos é inegável, porquanto resta avaliar sua relação com o capital social em jogo. Já a carga simbólica e os recursos materiais de mídia envolvidos nos eventos remeteriam ao capital comunicacional. Uma importante contribuição, aqui, seria analisar em que medida o capital social e comunicacional têm sido utilizados como instrumentos de cidadania (via comunicação pública) e de democracia (via comunicação política). Sem embargo, a comunicação política parece mostrar-se mais atuante do que a comunicação pública - ressalvas feitas a ações realizadas em decorrência de pressões, ao invés de derivadas de debates organizados. Seja como for, a assimetria observada entre comunicação pública e comunicação política, comparadas pela velocidade com que ações têm sido deflagradas, ainda precisa ser empiricamente fundamentada. Mas a pergunta que se faz é: tem havido realmente um desequilíbrio entre debate e ação?

\section{CONSIDERAÇÕES FINAIS}

Retornemos às hipótese avançadas no artigo. Quanto à hipótese de número 1, para a qual o capital social e 0 capital comunicacional possibilitariam a comunicação pública, é possível concluir que sim, pois foi mostrado que, embora a comunicação pública seja relativamente mais intensiva no uso de capital comunicacional, também o capital social cumpre importante função de mobilização e engajamento dos cidadãos que vão ao debate. Já a hipótese de número 2, que propunha uma passagem da comunicação pública (instância deliberativa) para a comunicação política (instância de ação), também se confirmou - embora o artigo tenha apontado, igualmente, que há ação na instância deliberativa e debate na instância de ação. Uma questão de ênfase, não de exclusividade. Em relação à hipótese de número 3, onde a cidadania redundaria em democracia participativa (em contraste com a representativa), tem-se a dizer: democracia participativa é pleonasmo, democracia representativa é oximoro .

A conclusão do artigo é que o capital social e o capital comunicacional são, de fato, recursos inatos em cada cidadão; recursos que precisam, ao mesmo tempo, ser desenvolvidos. Haveria, igualmente, uma passagem da comunicação pública (esfera de debate) para a comunicação política (instância decisória e de ação) - configurando uma espécie de "cidadania em ação". Aprofundar o papel dos capitais (social e comunicacional) e das comunicações (pública e política) para defesa, garantia e resgate dos direitos dos cidadãos, requer, ainda, pesquisas adicionais. Mas tais capitais e comunicações parecem estar contribuindo para a consolidação da democracia, no sentido de recolocar modernamente a questão do gerenciamento compartilhado da coisa pública. 


\section{REFERÊNCIAS}

ACHACHE, Gilles. La communication: déclin ou extension de la politique? Esprit, n. 164, p. 145-151, set. 1990.

BÉVORT, Antoine; LALLEMENT, Michel (Dir.). Le capital social: performance, equité et reciprocité. Paris : La Découverte/Mauss, 2006.

BOURDIEU, Pierre. Le capital social: notes provisoires. Actes de la Recherche in Sciences Sociales, 31, n. 31, p. 2-3, 1980.

BRAGA, José Luiz; LOPES, Maria Immacolata Vassalo de; MARTINO, Luiz C. (Org.). Pesquisa empírica em comunicação. São Paulo: Paulus, 2010.

BUCY, Erik P.; HOLBERT, R. Lance (Ed.). The sourcebook for political communication research: methods, measures, and analytical techniques. New York: Routledge, 2011.

CAÑEL, María José. Comunicación política: una guía para su estudio y práctica. Madrid: Tecnos, 1999.

CORREIA, João Carlos; FERREIRA, Gil Baptista; SANTO, Paula do Espírito (Org.). Conceitos de comunicação política. Covilhã, Portugal: LabCom Books, 2010.

DUARTE, Jorge. Sobre a emergência do(s) conceito(s) de comunicação pública. In: KUNSCH, Margarida M. Krohling (Org.). Comunicação pública, sociedade e cidadania. São Caetano do Sul, SP: Difusão Editora, 2011. p. 121-134.

FIGUEIREDO, Rubens (Org.). Marketing político em tempos modernos. Rio de Janeiro: Konrad-Adenauer-Stifung, 2008.

GIL, Patrícia G.; NOBRE, Heloiza H. M. Alternativas ao conceito e à prática da comunicação pública. Eptic On Line, v. 15, n. 2 , p. 12-27, 2013.

GRANJON, Fabien; LELONG, Benoît. Capital social, stratifications et technologies de l'information et de la communication. Revue Réseaux, n. 139, UMLV/Lavoisier, p. 149-173, 2006.

HABERMAS, Jürgen. Direito e democracia: entre facticidade e validade. Vol. II. Trad. de Flávio Beno Siebeneichler. Rio de Janeiro: Tempo Brasileiro, 1997.

JARAMILLO LÓPEZ, Juan Camilo. Advocacy: uma estratégia de comunicação pública. In: KUNSCH, Margarida M. Krohling (Org.). Comunicação pública, sociedade e cidadania. São Caetano do Sul, SP: Difusão Editora, 2011. p. 61-80.

KOÇOUSKI, M. Comunicação pública: construindo um conceito. In: MATOS, Heloiza(Org.). Comunicação pública:interlocuções, interlocutores e perspectivas. São Paulo: ECA-USP, 2012. p. 71-96.

KUNSCH, Margarida M. Krohling. Comunicação pública: direitos de cidadania, fundamentos e práticas. In: MATOS, Heloiza (Org.). Comunicação pública: interlocuções, interlocutores e perspectivas. São Paulo: ECA-USP, 2011. p. 13-22.

MAIA, Rousiley C. M.; GOMES, Wilson; MARQUES, Francisco P. J. A. (Org.). Internet e participação política no Brasil. Porto Alegre: Sulina, 2011. 
MARQUES, Ângela C. Salgueiro. As interseções entre o processo comunicativo e a deliberação pública. In: MARQUES, Ângela C. Salgueiro (Org.). A deliberação pública e suas dimensões políticas comunicativas: textos fundamentais. Belo Horizonte: Autêntica Editora, 2009. p. 11-28.

MATOS, Heloiza Engajamento cívico e participação política: controvérsias entre as TIC's e o declínio do capital social. In: ENCONTRO BRASILEIRO DE PESQUISADORES EM COMUNICAÇÃO E POLÍTICA, IV, Uerj, Rio de Janeiro, 13-15 de abril de 2011. Anais... São Paulo: Compolitica - Associação Brasileira de Pesquisadores em Comunicação e Política, 2011.

MATOS, Heloiza Ação política e propaganda eleitoral. Comunicação e Educação, São Paulo, ECA-USP, v. VII, n. 19, p. 25-31, 2000.

MATOS, Heloiza NOBRE, Guilherme Fráguas. Capital comunicacional. In: CONGRESSO LUSOCOM, 8ㅜㅜ, 2009, Lisboa. Anais... Lisboa: Universidade Lusófona, 2009. p. 78-91.

NOBRE, Guilherme Fráguas. Capital social, comunicação pública e deliberação: a gestação do capital comunicacional público. In: MARQUES, Ângela; MATOS, Heloiza. Comunicação e política: capital social, reconhecimento e deliberação pública. São Paulo, Summus, 2011.

NOBRE, GUILHERME Fráguas; MATOS, Heloiza Capital comunicacional turístico. In: CITURISMO 2010. Peniche, Instituto Politécnico de Leiria, 2010.

NORRIS, Pippa. Did television erode social capital? A reply to Putnam. Political Science and Politics, v. XXIX, n. 3, p. 474-480, set. 1996.

PONTHIEUX, Sophie. Le capital social. Paris: La Découverte, 2006.

PORTES, Alejandro. Capital social: origens e aplicações na sociologia contemporânea. Sociologia: Problemas e Práticas, n. 33, p. 133-158, 2000.

PUTNAM, Robert D. Solo en la Bolera: colapso y resurgimiento de la comunidad norteamericana. Barcelona: Galaxia Gutenberg, 2002.

Comunidade e democracia: a experiência da Itália moderna. Rio de Janeiro: Editora FGV, 1996.

RECUERO, Raquel da Cunha. Redes sociais na internet. Porto Alegre: Sulina, 2009.

WEBER, Maria Helena. Estratégias da comunicação de Estado e a disputa por visibilidade e opinião. In: KUNSCH, Margarida M. Krohling (Org.). Comunicação pública, sociedade e cidadania. São Caetano do Sul, SP: Difusão Editora, 2011. p. 101-120.

ZÉMOR, Pierre. (1995). La communication publique. 3. ed. Paris: PUF, 2005.

Artigo recebido em 29.08.2013 e aprovado em 25.11.2013. 